\title{
Debut de lupus eritematoso sistémico con síndrome antifosfolipídico catastrófico: beneficio del tratamiento precoz
}

\author{
R. RUIZ DOMÍNGUEZ, I. HUANCA MAMANI' \\ Departamento de Medicina Interna. ${ }^{~}$ Servicio de Nefrología. Hospital Materno Infantil. \\ Caja Nacional de Salud. Miraflores. Perú
}

\begin{abstract}
DEBUT OF SYSTEMIC LUPUS ERITEMATOUS WITH CATASTROP HIC ANTIPHOSPHOLIPID SYNDROME: BENEFIT OF THE EARLY TREATMENT
\end{abstract}

\section{RESUMEN}

La denominación de Síndrome Antifosfolipídico (SAF) "catastrófico" fue empleada para definir una forma grave y rápidamente evolutiva de SAF que conduce a fallo multiorgánico. Todos desarrollan accidentes oclusivos en un corto periodo (días a semanas), siendo el índice de mortalidad del $50 \%$. En su tratamiento se han utilizado glucocorticoides, heparina, recambio plasmático, ciclofosfamida y gammaglobulinas intravenosas.

El presente caso es de una paciente de sexo femenino, con diagnóstico de lupus eritematoso sistémico, con anticuerpos anticardiolipina, anti ribonucleoproteína (anti RNP) y afectación multiorgánica que sobrevivió gracias al tratamiento precoz y multidisciplinario.

PALABRAS CLAVE: Lupus eritematoso sistémico. Síndrome antifosfolipídico catastrófico. Anticuerpos anti U1-RNP.
ABSTRACT

The Catastrophic Antiphospholipid Syndrome (CAS) results in multiorgan system failure. All patients develop occlusive accident in a short period (days to weeks), with a mortality of 50\%. Treatment can include glucocorticoids, heparin, plasmatic exchange, ciclofosfamide and intravenous globulin.

The present article treat of female patient lairs Systemic Eritematous Lupus (SLE), anticardiolipine antibodies, anti ribonucleoprotein antibodies (antiRNP) and multiorgan systemic failure, she survived thanks to the multidisciplinary a early treatment.

KEY WORDS: Systemic Lupus Eritematous, Catastrophic Antiphospholipid Syndrome. Anti U1-RNP antibodies.

Ruiz Domínguez R, Huanca Mamani I. Debut eritematoso sistémico con síndrome antifosfolipídico catastrófico: beneficio del tratamiento precoz. An Med Interna (Madrid) 2007; 24: 339-341.

\section{INTRODUCCIÓN}

El Lupus Eritematoso Sistémico (LES) está considerado como el prototipo de la enfermedad autoinmune en la que la formación de inmunocomplejos tiene efectos patógenos (1). Se asocia a síndrome antifosfolipidico (SAF) en el 50\% de los casos, algunas veces catastrófico con una prevalencia, menor al $1 \%$. (1-5).

El síndrome antifosfolipidico es una enfermedad definida por la presencia de Ac. AFL (Ac. anticardiolipina y/o anticoagulante lúpico)(6-7-11). Puede presentarse en ausencia de otras enfermedades autoinmunes, denominándose entonces Síndrome Antifosfolipidico Primario (SAF. primario), es más frecuentemente asociado a LES o similares $(1,4,7,8)$. Clínicamente se caracteriza por: abortos a repetición, trombocitopenia y variados síndromes neurológicos relacionados, fundamentalmente, con fenómenos trombóticos venosos y arteriales (11-16). Una forma rara de SAF es el denominado catastrófi- co, termino empleado para definir una forma grave y rápidamente evolutiva de SAF que conduce a insuficiencia multiorgánica. Se presenta un caso a propósito de estos síndromes.

\section{CASO APORTADO}

Se trata de una paciente de 28 años de edad, sin antecedente de enfermedades previas, con cuadro clínico caracterizado por síndrome toxico infeccioso completo y poli-artralgias en articulaciones mayores, de siete días de evolución, tratada con amoxicilina vía oral sin remisión de cuadro, asociándose tos productiva con expectoración muco-purulenta, disnea progresiva de medianos a pequeños esfuerzos, deposiciones líquidas y sintomatología urinaria.

Al examen físico: malas condiciones generales, P.A. 110/60 mmHg, F.C. 100 latidos/minuto, F.R. 24 /minuto, con piel y mucosas secas, pálidas. En cráneo, región parietal con zonas de alopecia, se observa eritema centro-facial de mayor intensidad en mejillas, pulmones con condensación incompleta subescapular derecha y sustitu- 
ción contra-lateral. Abdomen blando, doloroso en hipocondrio y flanco derechos, Blumberg positivo. Genitales con flujo genital blanco-amarillento. En extremidades superiores se observa livedo reticularis en dorso de manos, cianosis distal en dedos de ambas manos, con disminución de la temperatura local y lesiones en "mordedura de ratón" en terceras falanges del $2^{\circ}$ y $3^{\circ}$ dedos de mano derecha, y en terceras falanges del $1^{\circ}, 3^{\circ}$ y $5^{\circ}$ dedos de mano izquierda, dolorosas a la palpación además de hemorragias sub-ungueales en astilla. Edema esbozado en extremidades inferiores, petequias en dorso de ambos pies, confluentes. Conciente, orientada, sin datos de irritación meníngea ni de focalización neurológica.

Laboratorio: hemoglobina 10,3 g/dl, hematocrito 31\%, VES 105 $\mathrm{mm}$. leucocitos $10.000 \mathrm{~mm}^{3}$, segmentados $8300 / \mathrm{mm}^{3}$, linfocitos $1500 / \mathrm{mm}^{3}$, monocitos $100 / \mathrm{mm}^{3}$, plaquetas $200.000 \mathrm{~mm}^{3}$, glucemia pre-prandial $159 \mathrm{mg} / \mathrm{dl}$, Na sérico $143 \mathrm{mmol} / \mathrm{l}$, K sérico 4,2 mmol/l Cl. serico $118 \mathrm{mmol} / \mathrm{l}$, nitrógeno ureico sérico $46,9 \mathrm{mg} / \mathrm{dl}$, creatinina $2,9 \mathrm{mg} / \mathrm{dl}$, tiempo de protrombina 12 segundos, con actividad del $100 \%$. Examen de orina: proteínas ++ , sangre ++ , hematíes 50 a 60 , piocitos de 40 a 50 , presencia de cilindros hematicos y granulosos.

PCR 2,6 mg/dl $(<0,8)$, factor reumatoide $(+)$ 1,3 UI/ml (menor 8), ASTO $50(<200)$, serología para hepatitis B, C, VIH negativas, TSH 5,54 uU/ml $(0,63-4,19)$, T3 $0,07 \mathrm{nmol} / \mathrm{L}(1,3-2,5)$ у T4 29 $\mathrm{nmol} / \mathrm{l}(69-141)$, prolactina $36,20 \mathrm{ng} / \mathrm{ml}(3,6-18,9)$, curva de tolerancia a la glucosa alterada, pruebas de función hepática normales. Hemocultivo, coprocultivo y urocultivo negativos. Proteinuria en orina de $24 \mathrm{~h}: 899 \mathrm{mg}$. Complemento $3,12 \mathrm{mg} / \mathrm{dl}$ (70-170) y complemento 4, $0 \mathrm{mg} / \mathrm{dl}$ (20-40). ANA patrón difuso y periférico (+) 1:320 $(<1 / 40)$ y antiDNA ds $(+) 64 \mathrm{UI} / \mathrm{ml}(<27)$ perfil de antigenos extraíbles del núcleo (ENA) con JO-1 dudoso $0,92(<0,90) \mathrm{Sm} / \mathrm{RNP}$ positivo $1,2(<0,37)$. Anticuerpos antifosfolipídicos: anticardiolipina IgM $24 \mathrm{MPL} / \mathrm{ml}(<12)$ e IgG $21 \mathrm{GPL} / \mathrm{ml}(<13)$.

Serología viral: con toxoplasma IgG ELISA positiva $2,1(>1,1)$, citomegalovirus IgG ELISA positiva $4,4(>1,1)$ e IgM ELISA positiva $2,8(>1,1)$.

Se suman durante su internación datos de trombosis venosa profunda en extremidad inferior izquierda verificada por Eco Doppler venoso, derrame pericardio severo corroborado por Rx de tórax, electrocardiograma, ecocardiografía Doppler y acrocianosis en falanges distales de dedos de ambas manos. Se realizaron pulsos con metilprednisolona de $500 \mathrm{mg}$ por 3 días consecutivos, se continúo con prednisona a dosis de $1 \mathrm{mg} / \mathrm{kg}$ /día y azatioprina $100 \mathrm{mg} /$ día, además de anticoagulación con heparina sódica y warfarina.

La evolución fue desfavorable (Fig. 1 y 2), con necrosis digital (gangrena seca), se asociaron signos de psicosis, de nefropatía lúpica y de isquemia cerebral (hemiparesia izquierda), documentados con TAC de cerebro y electroencefalograma. Fue tratada con 3 sesiones

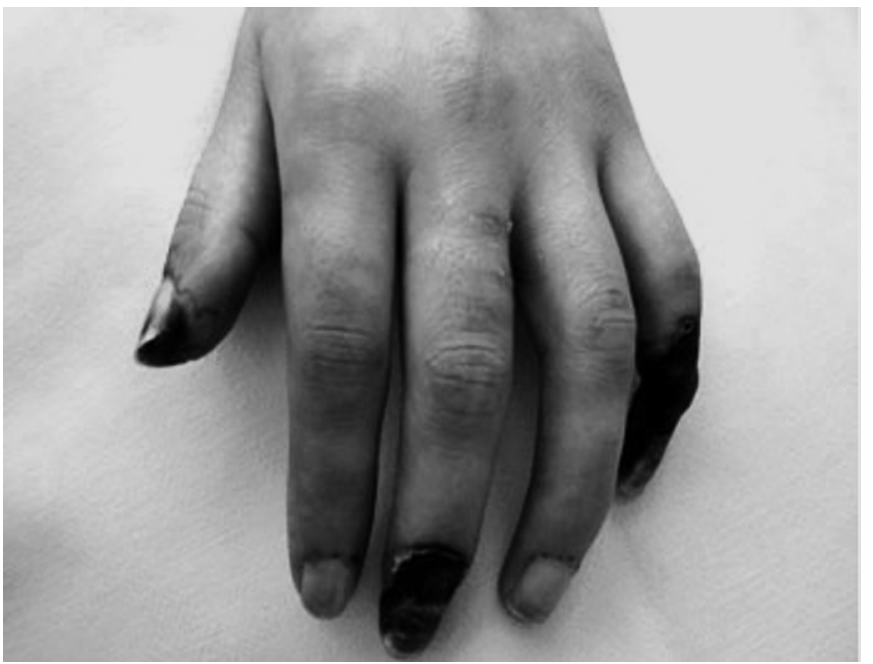

Fig. 1. Necrosis en dedos y livedo en dorso de mano izquieda.

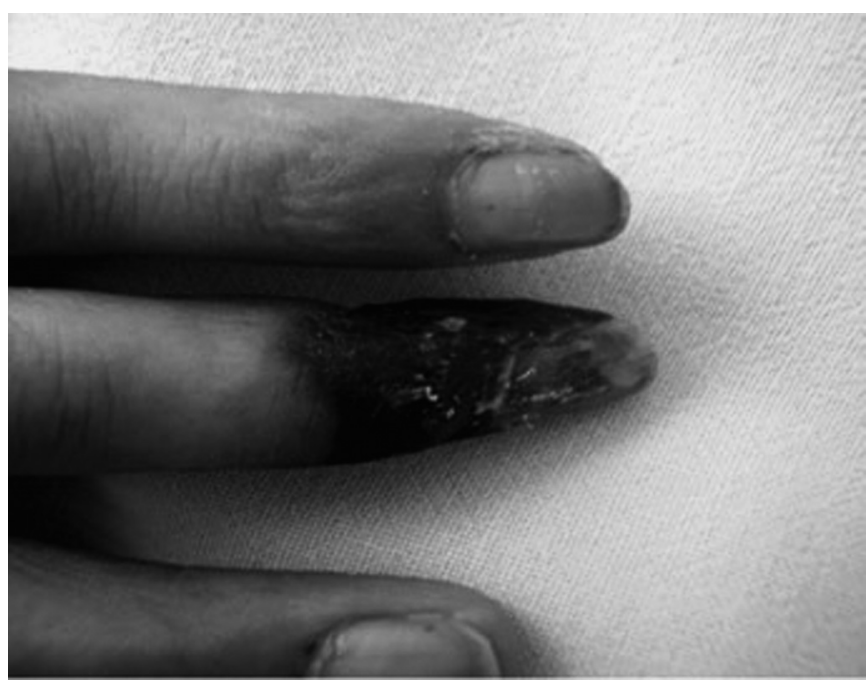

Fig. 2. Necrosis en dedos de mano derecha.

de plasmaferesis semanales durante dos semanas, pulsos con $1 \mathrm{~g}$ de ciclofosfamida semanales por 3 semanas consecutivas e inmunoglobulina $20 \mathrm{~g}$ por día ( $400 \mathrm{mg} / \mathrm{kg} /$ día) por 7 días, pentoxifilina, flunarizina, levotiroxina, antivirales y antihipertensivos IECA, con evolución favorable. Es dada de alta tras 6 semanas de internación con secuelas neurológicas y necrosis completa de $1^{\mathrm{a}}$ y $2^{\mathrm{a}}$ falanges distales de los dedos mencionados en ambas manos, las cuales se amputaron naturalmente a los 9 meses de su alta. Actualmente está con controles médicos periódicos y tratamiento con micofenolato mofetilo $1 \mathrm{~g} /$ día con evolución favorable.

\section{DISCUSIÓN}

Para el diagnostico de LES se busca el cumplimiento de 4 de los 11 criterios de clasificación de la Asociación Americana de Reumatología (ARA). Sin embargo, de estos, sólo los 2 últimos criterios toman en cuenta la elevación en el título de auto anticuerpos y específicamente solo de anti DNA y ANA $(3,4,9,10)$. Se asocia a SAF en el $50 \%$ de los casos y a SAF "catastrófico en el $1 \%$ de los casos.

El SAF "catastrófico" es una forma rara y grave de SAF que se caracteriza por:

1. Evidencia de afección de 3 órganos o más, sistemas y/o tejidos.

2. Desarrollo de manifestaciones simultáneamente o en menos de una semana.

3. Confirmación anatomopatológica de la oclusión de los vasos de pequeño calibre en, por lo menos, un órgano o tejido.

4. Confirmación de laboratorio de la presencia de anticuerpos antifosfolipídicos.

SAF catastrófico definitivo

Los 4 criterios

SAF catastrófico probable

Los 4 criterios, excepto la afección de sólo 2 órganos, sistemas y/o tejidos.

Los 4 criterios, excepto la ausencia de confirmación de laboratorio $(2,9,22)$.

La isquemia cerebral es el evento trombótico arterial más frecuente (19-21), además de trombosis de arterias dístales que pueden conducir a isquemia, gangrena y necrosis digital $(5,13,17,18)$. Pueden existir diferentes manifestaciones cutá- 
neas, siendo las más frecuentes la livedo reticularis y las úlceras cutáneas. $(16,18)$.

La mortalidad del SAF catastrófico llega al 50\%. El tratamiento del cuadro debe ser de instauración precoz con glucocorticoides, ciclofosfamida, gammaglobulinas endovenosas, recambios plasmáticos y anticoagulación intensa ya que simplemente la inmunosupresión no da resultados satisfactorios $(2,22)$.

En el presente caso se identificaron como características de SAF “catastrófico: afectación de 3 órganos o sistemas, manifestaciones simultáneas en menos de 1 semana y pruebas de laboratorio positivas para anticuerpos antifosfolipidicos (222), que asociados a las alteraciones en los anticuerpos del complejo ENA y otros, justifican la múltiple afectación orgánica y severidad del cuadro (1). Los anticuerpos anti RNP positivos, se han relacionado con trombosis en arterias $\mathrm{y}$ venas distales y con gangrena y necrosis en dedos, datos que se correlacionan con el caso presentado (5-13).

\section{Bibliografía}

1. Levine JS, Branch W, Rauch J. The Antiphospholipid syndrome. N Engl J Med 2002; 346: 752-763.

2. AAsherson RA. Catastrophic antiphospholipid syndrome: International consensus statement on classificationcriteria and treatment guidelines. Lupus 2003; 12 (7): 530-534.

3. Villardell Tanés M, Ordi Ros J. Lupus eritematoso sistémico. Farreras Rozman, Medicina Interna, $14^{\mathrm{a}}$ edición. Ediciones Harcout S.A. 2000; 147: 1260-1267.

4. Bobba RS, Johnson SR, Davis AM. A review of the Sapporo and Revised Sapporo Criteria for the Clasification of Antiphospholipid Syndrome. Where Do the Revised Sapporo Criteria add Value? J Rheumatol. 2007; 4: 221-24.

5. Mc Mahon MA, Keogan M, O Connell P, Kearns G. The prevalence of Antiphospholipid Antibody Syndrome Among. Ir Med J 2006; 99: 2968.

6. ML Bertolaccini and MA Khamashta. Laboratory diagnosis and management challenges in the Antiphospholipid Syndrome. Lupus, March 1,2006; 15: 172-178

7. Lim W, Crowther MA, Eikelboom JW. Management of antiphospholipid antibody syndrome: A systematic review. JAMA 2006; 295: 10501057.

8. Bermas BL, Schur PH, Kaplan AA. Treatment of the antiphospholipid syndrome. Uptodate; 2007.

9. Cervera R, Font J, Gomez-Puerta JA, Espinosa G, Cucho M, Buccianelli S, et al. Validation of the preliminary criteria for the classification of catastrophic antiphospholipid syndrome. Ann Rheum Dis 2005; 64: 1205-1209.

10. Vora SK, Asherson RA, Erkan D. Catastrophic antiphospholipid syndrome. J Intensive Care Med 2006; 21: 144-159.

11. Cruz DPD. Systemic lupus erythematosus. BMJ 2006; 332: 890-894.

12. Ruiz-Irastorza G, Khamashta MA. Antiphospholipid síndrome: Treatment controversias. Future Rheumatol 2006; 1: 345-353.

13. Leroux MB, Barraza S, Estrella V, Bearzotti M. Síndrome anticuerpo antifosfolipídico. Arch Argent Dermatol 2000; 50: 109-115.

14. Asherson RA, Espinosa G, Cervera R, Gómez-Puerta JA, Mesuruana J,
Se reporta pronóstico malo en casos similares, a pesar de ello se sugiere el tratamiento precoz y multidisciplinario, con recambios plasmáticos y anticoagulación a altas dosis, ya que tan solo el tratamiento inmunomodulador en forma aislada no ha dado buenos resultados, todo ello con el fin de limitar la afectación orgánica y mejorar la sobrevida (2-22). Con la paciente se limitó la afectación orgánica gracias al manejo multidisciplinario y el inicio precoz del tratamiento, pero lamentablemente no se pudieron revertir las secuelas que quedaron como consecuencia de la actividad de la enfermedad; sin embargo, con el presente caso, se demuestra que el diagnóstico temprano más el inicio de un tratamiento precoz y multidisciplinario mejora el pronóstico y la sobrevida de los pacientes.

El síndrome antifosfolipidico catastrófico singue siendo considerado como enfermedad rara, sin embargo debe ser tomado en cuenta por su agresividad y fatalidad en pacientes portadores de enfermedades autoinmunes en nuestro medio.
Bucciarelli $\mathrm{S}$, et al. Disseminated intravascular coagulation in catastrophic antiphospholipid syndrome: clinical and haematological characteristic of 23 patients. Ann Rheum Dis 2005; 64: 943-946.

15. Nanete N, Macías P, Jaén F, Hidalgo C, Cáliz R, Jiménez-Alonso J. Two cases of catastrophic antiphospholipid síndrome. Lupus 2005; 14; 907-909.

16. Levine SR, Brey RL, Joseph CLM, Havstad S. Risk of recurrent thromboembolic events in patients with focal cerebral ischemia and Antiphospholipid antibodies. Stroke 1992; 23 (Supl. I): I-29-I-32.

17. Lie JT. Vasculopathy in the antiphospholipid syndrome: thrombosis or vasculitis, or both? J Rheumatol 1989; 16: 713-5.

18. Rosove $\mathrm{MH}$, Brewer PMC. Antiphospholipid thrombosis: clinica course after the first thrombotic event in 70 patients. Ann Intern Med 1992; 117: 303-308.

19. Erkan D, Asherman R, Espinosa G, Cervera R, Font J, Lock Shim M. Long term autcome of Catastrophic Antiphospholipid Syndrome survivors. Ann Rheum Dis 2003; 62: 530-533.

20. Dessailloud R, Papo T, Vaneecioo S, Gamblin C, Vanhille P, Pielle JC Acalculous ischemic gallbladder necrosis in the catastrophic antiphospholipid syndrome. Arthritis Rheum 2004; 41: 1318-1320.

21. Herranz MT, Rivier G, Khamashta MA, et al. Association between antiphospholipid antibodies and epilepsy in patients with systemic lupus erythematosus. Arthritis Rheum 1994; 37: 568-571.

22. Shoenfeld Y, Blank M, Cervera R, Font J, Raschi R, Meroni PL. Infections origin of the Antiphospholipid Syndrome, Ann Rheum Dis 2006 65: 2-6.

23. Linenberger ML, Price TH. Use of cellular and plasma Apheresis in the critically patients: Part 2: clinical indications and applications. J Intensive Care Med 2005; 20: 88-103.

24. Crowther MA, Ginsberg JS, Julian J, Math M, Denburg J, et al. A comparison of two intensities of warfarin for the prevention of recurrent thrombosis in patients with the antiphospholipid antibody syndrome. N Engl J Med 2003; 349: 1133-38.

25. Lockshin MD, Erkan D. Treatment of the antiphospholipid syndrome. N Engl J Med 2003; 349: 1177-1179. 